\title{
Nucleic Acid Scanning Techniques Distinguish Closely Related Cultivars of Poinsettia
}

\author{
Terri Woods Starman, Xiangrong Duan, and Shane Abbitt \\ Department of Ornamental Horticulture and Landscape Design, Institute of \\ Agriculture, University of Tennessee, Knoxville, TN 37901-1071
}

Additional index words. arbitrary primers, amplification profiles, ASAP, DNA amplification fingerprinting, Euphorbia pulcherrima

\begin{abstract}
DNA amplification fingerprinting (DAF) was used to evaluate the genetic relationships among 11 cultivars of poinsettia (Euphorbia pulcherrima Willd.). Amplification was with 10 octamer oligonucleotide primers that generated 336 DNA bands. Thirtyone percent of the bands were polymorphic and distinguished among cultivars. Genetic relationships were evaluated by cluster analysis, and the resulting dendrogram closely agreed with published cultivar relationships. Arbitrary signatures from amplification profiles (ASAP) were further used to characterize two cultivars, 'Nutcracker Red' and 'Peterstar Red', that were previously found to be genetically and morphologically similar, as well as five cultivars in the "Freedom" series. The DAF products generated with arbitrary octamer primers were reamplified with mini-hairpin decamer primers in these experiments. The ASAP profiles were complex and yielded a total of 231 bands, $38 \%$ of which were polymorphic and capable of distinguishing each Freedom cultivar. Five of the eight primer combinations distinguished 'Nutcracker Red' from 'Peterstar Red'. Thus, closely related cultivars of poinsettia can be separated using new and improved molecular fingerprinting protocols.
\end{abstract}

In recent years, breeders have introduced many new poinsettia cultivars to the industry to provide more diversity of plant types and bract colors for the profitable Christmas potplant market. Cultivars introduced after 1960 have been seedling selections of diverse parentage initially produced by cross-pollination (Ecke, 1990). Generally, after 4 to 5 years, the best selections are exposed to X-ray or gamma radiation to create genetic mutations leading to new bract colors, including pink, spotted, marbled, and bicolor types (Ecke, 1990).

Presently, poinsettia breeders emphasize morphological traits, such as bract color intensity, growth habit, and earliness to flower, for determining genetic purity when applying for plant patents. The ability to unequivocally distinguish individuals is paramount in cultivar identification, marker-assisted selection (MAS), and genetic mapping applications. Morphological characteristics differ under varying environments. Therefore, nucleic acidbased fingerprinting capable of producing characteristic genetic patterns has been sought for poinsettia cultivar protection and certification.

Applications for DNA marker technology in floriculture are expanding as the technology becomes easier and less expensive to use. For

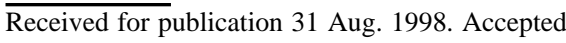
for publication 7 Jan. 1999. Use of trade names does not imply endorsement of the products named nor criticism of similar ones not named. The cost of publishing this paper was defrayed in part by the payment of page charges. Under postal regulations, this paper therefore must be hereby marked advertisement solely to indicate this fact.
}

example, randomly amplified polymorphic DNA (RAPD) analysis was used to test for genetic purity in inbred parental lines of petunia (Petunia $\times$ hybrida Hort. Vilm.-Andr.) and cyclamen (Cyclamen persicum Mill.) and to verify heterosis during production of $\mathrm{F}_{1}$ hybrids (Jianhua et al., 1997). Similarly, 24 accessions of Rosa laevigata Michx. (Cherokee rose) found in plantings and nurseries throughout the southeast United States were found to be ramets of two major clones (Walker and Werner, 1997). Finally, DNA probes and polymerase chain reaction (PCR) detected phytoplasma organisms that cause branching in free-branching poinsettia cultivars (Lee et al., 1997).

The DNA amplification fingerprinting (DAF) method (Caetano-Anollés et al., 1991), which differs from RAPD analysis by template and primer concentration and primer length, has been utilized with floral crops including petunia, geranium (Pelargonium sp.), and chrysanthemum (Dendranthema $\times$ grandiflora Kitam.). In a study designed to identify the putative parental line of $P . \times$ hybrida, DAF distinguished between Petunia inflata R.E. Fries, P. integrifolia (Hook.) Schinz \& Thell., and $P$. violace Lindl., three violet-flowered species that were very similar morphologically (Cerny et al., 1996). Use of DAF also separated two white-flowered species of Petunia and characterized 10 cultivars of Petunia $\times$ hybrida and grouped them by flower color within the dendrogram (Cerny et al., 1996).

Using the DAF technique, many DNA polymorphisms were found between members of six commercial chrysanthemum series (Scott et al., 1996). Although the average distance among series was 10-fold greater than among cultivars within a series, a number of polymorphic loci could uniquely identify closely related cultivars within a series. In contrast, the RAPD technique could not distinguish chrysanthemum cultivars within the series (Wolff and Peters-Van Rijn, 1993).

Recently, a new fingerprinting strategy, arbitrary signatures from amplification profiles (ASAP) (Caetano-Anollés and Gresshoff, 1996), has been used to distinguish closely related plant material. The ASAP strategy is a new, dual-step amplification procedure whereby amplification products generated with arbitrary primers are reamplified using minihairpin primers containing 3 '-terminal, threenucleotide, arbitrary sequences. These minihairpin primers produce complex fingerprints and detect increased levels of polymorphic DNA (Caetano-Anollés and Gresshoff, 1994). The ASAP method has been used to distinguish among eight cultivars of two geranium species, Pelargonium $\times$ hortorum L.H. Bail. (cutting and seed geranium) and $P$. peltatum (L.) L'Hér. ex Ait. (ivy geranium) (Starman and Abbitt, 1997). Phenetic analysis revealed that seed geraniums (diploids) were clustered in one group, cutting geraniums (tetraploids) were clustered together, and the ivy geranium cultivars were separate from the other species. Furthermore, all cultivars within two series of seed geranium were distinguished. The ASAP method was used to distinguish mutants and sports within the Charm series of chrysanthemum (Trigiano et al., 1998). Our objective in this study was to determine the feasibility of using the new DNA fingerprinting techniques for unambiguously distinguishing and identifying poinsettia cultivars.

\section{Materials and Methods}

Plant material. The 11 cultivars of poinsettia used in this study were 'Celebrate 2', 'Darlyne', 'Freedom Red', 'Lilo Red', 'Nutcracker Red', 'Peterstar Red', 'Petoy', 'Red Sails', 'Supjibi', 'V-14 Glory', and 'V-17 Angelika'. 'Nutcracker Red' and 'Peterstar Red' were used because of their morphological similarity. Five cultivars of the Freedom series used were 'Freedom Red', 'Freedom Pink', 'Freedom White', 'Freedom Marble' (pink and white bicolor bracts), and 'Freedom Jingle Bells' (red- and pink-spotted bracts). The Freedom series cultivars are uniform in growth habits, i.e., early flowering, large bracts, dark leaves, and short and compact growth.

Young, expanding $(\approx 1-2 \mathrm{~cm}$ in length) leaves were collected for DNA extraction from plants that were being grown in a cultivar trial according to standard floricultural practices. Leaf tissue was collected in early morning, frozen in liquid nitrogen, and stored immediately at $-80^{\circ} \mathrm{C}$ until needed for DNA extraction. Equal quantities of leaf tissue from five individual plants of each cultivar were bulked in the greenhouse. The DNA from individual plants was bulked as a strategy to avoid plantto-plant variation.

DNA extraction. Extractions of the leaf tissue $(\approx 50 \mathrm{mg})$ were performed using the 
Puregene Kit (Gentra Systems, Research Triangle Park, N.C.). The extracted DNA was quantified using a TKO 100 mini-fluorimeter (Hoefer Scientific Instruments, San Francisco) and the fluorescent intercalating agent Hoechst 33258.

DNA amplification. Analysis by DAF followed the protocol of Caetano-Anollés et al. (1991). The reaction cocktail $(20 \mu \mathrm{L})$ contained 9.2 $\mu \mathrm{L}$ deionized $\mathrm{H}_{2} \mathrm{O}, 2 \mu \mathrm{L}$ deoxyribonucleosides (200 $\mu \mathrm{M}$ of each dNTP), $1.2 \mu \mathrm{L}$ $\mathrm{MgCl}_{2}$ (25 mM stock), $2 \mu \mathrm{L}$ primer (30 $\mu \mathrm{M}$ stock), $2 \mu \mathrm{L}$ reaction buffer [10 mM Tris, 10 mм KCl (pH 8.3)], $3 \mu \mathrm{L}$ DNA template (diluted to $1.0 \mathrm{ng} \cdot \mu \mathrm{L}^{-1}$ with deionized sterile $\mathrm{H}_{2} 0$ ), and $0.6 \mu \mathrm{L}$ DNA polymerase (10 units/ $\mu \mathrm{L})$ Ampli-Taq Stoffel Fragment (PerkinElmer/Cetus, Norwalk, Conn.). Ten octamer primers were screened (Table 1). The DNA was amplified in a twin-block thermocycler (Ericomp, San Diego) with 35 cycles (30 s at $96^{\circ} \mathrm{C}, 30 \mathrm{~s}$ at $30^{\circ} \mathrm{C}$, and an extension phase of $30 \mathrm{~s}$ at $72^{\circ} \mathrm{C}$ ).

The ASAP strategy (Caetano-Anollés and Gresshoff, 1996) followed a cascade amplification protocol whereby amplification with two octamer primers $(8.6 \mathrm{D}$ and $8.7 \mathrm{D})$ was followed by reamplification with one of four different mini-hairpin primers, HpA12 (GCGAAAGC-CGA), HpB52 (GCGACAGC-ACA), HpC19(GCGAGAGCTCG), and HpD4 (GCGATAGC-CCA). The ASAP amplification reaction was contained in a final volume of $20 \mu \mathrm{L}: 6 \mu \mathrm{L}$ deionized $\mathrm{H}_{2} \mathrm{O}$, $2 \mu \mathrm{L}$ deoxyribonucleosides ( $200 \mu \mathrm{M}$ of each dNTP), $1.2 \mu \mathrm{L} \mathrm{MgSO}_{4}$ (67 mm stock), $6 \mu \mathrm{L}$ primer (30 $\mu \mathrm{M}$ stock), $2 \mu \mathrm{L}$ reaction buffer (10X TTNK), $2 \mu \mathrm{L}$ DAF template (1:50 dilution of the DAF amplification), and $0.8 \mu \mathrm{L}$ DNA polymerase (10 units $/ \mu \mathrm{L})$ Ampli-Taq Stoffel Fragment.

Separation and staining. The DNA amplification fragments were separated using polyacrylamide gel electrophoresis (PAGE) (Caetano-Anollés and Gresshoff, 1994) with modification (Bassam and Bentley, 1995). The fragments were then silver-stained (Bassam et al., 1991) for visualization.

Data analysis. A total of 10 DAF primers were used in the analysis of the 11 poinsettia cultivars. A total of eight primer combinations (two octamers $\times$ four mini-hairpins) were used in the analysis of 'Nutcracker Red', 'Peterstar Red', and the Freedom series. Bands generated by each primer or primer combination ( $\leq 1000$ bp in length) were visually scored on a light box as present (1) or absent (0). At least two gels for each primer $\times$ cultivar combination were compared to ensure that the profiles were consistent. In a few cases, questionable products were assigned as missing data. To estimate genetic distance among taxa, Jaccard similarity coefficients were computed using the simple matching method of the NTSYS-pc program (numerical taxonomy and multivariate analysis system; version 1.8, Exeter Software, Setauket, N.Y.). The resultant matrix was then used in the sequential agglomerative hierarical nested (SAHN) clustering procedure to analyze relationships among cultivars. Both an unweighted pair group cluster analy-
Table 1. DAF primers, primer sequences, number of bands produced, polymorphic bands, and unique profiles among 11 poinsettia cultivars.

\begin{tabular}{|c|c|c|c|c|}
\hline $\begin{array}{l}\mathrm{DAF} \\
\text { primer }\end{array}$ & Primer sequence $5^{\prime}-3^{\prime}$ & $\begin{array}{l}\text { No. of } \\
\text { bands }\end{array}$ & $\begin{array}{c}\text { No. of } \\
\text { polymorphisms }\end{array}$ & $\begin{array}{c}\text { No. of unique profiles } \\
\text { (11 total) }\end{array}$ \\
\hline $8.6 \mathrm{~A}$ & GAGCCTGT & 43 & 13 & 6 \\
\hline $8.6 \mathrm{D}$ & GTAACGCC & 43 & 14 & 9 \\
\hline $8.6 \mathrm{~F}$ & GATCGCAG & 40 & 13 & 5 \\
\hline $8.6 \mathrm{G}$ & CTAACGCC & 31 & 7 & 1 \\
\hline $8.6 \mathrm{~J}$ & GTATCGCC & 33 & 12 & 7 \\
\hline $8.7 \mathrm{~A}$ & AATGCAGC & 19 & 8 & 2 \\
\hline $8.7 \mathrm{D}$ & CCGAGCTG & 33 & 13 & 5 \\
\hline $8.7 \mathrm{~F}$ & CGTGGTGG & 24 & 6 & 6 \\
\hline $8.7 \mathrm{I}$ & CCTGCTGG & 30 & 10 & 5 \\
\hline $8.7 \mathrm{M}$ & CAGCTCGG & 40 & 9 & 3 \\
\hline
\end{tabular}

sis (UPGMA) and principal coordinate analysis (PCO) were used.

\section{Results and Discussion}

DAF analysis of poinsettia cultivars. The DAF protocol was used for distinguishing the 11 poinsettia cultivars that had red bracts (except 'Darlene', with pink bracts) but differed from each other in earliness to flower, branching habit, foliage color, size of bracts and cyathia, and postharvest keeping quality. Use of 10 different octamer primers gave distinctive electrophoresis patterns for all 11 cultivars (Fig. 1), generating 336 DNA bands. The average number of bands $(\leq 1000 \mathrm{bp})$ per primer was 34, ranging from 19 to 43 (Table 1). Thirty-one percent of the bands were polymorphic and distinguished the cultivars. The number of unique profiles per primer varied from one to nine among cultivars. The resulting dendrogram closely agreed with published cultivar relationships (Fig. 2). For example, 'Peterstar Red' is a sport of 'V-17 Angelika' and 'Darlyne' is part of the series of color sports arising from 'Supjibi'. 'Petoy' is an improved cultivar of 'Supjibi', morphologically similar but late-flowering, taller, and less susceptible to bract edge burn. Cultivars clustered into three main groups. Those cultivars that clustered with 'V-14 Glory' are its descendants and all have small cyathia. Likewise, those cultivars that clustered with ' $\mathrm{V}-17$ Angelika' have large cyathia and some are known descendants.

In a study of nine poinsettia cultivars using RAPD markers, a dendrogram was developed using nine primers (Ling et al., 1997). Fiftyseven primers were screened to find 15 that revealed polymorphisms, while the other 42 primers produced monomorphic patterns. Their results resembled ours in that no single RAPD primer produced polymorphic bands in all cultivars. However, in both studies all cultivars were distinguishable with the combinations of polymorphic bands generated by various primers.

ASAP analysis of closely related cultivars and a poinsettia series. 'Nutcracker Red' and 'Peterstar Red' were separated by the DAF analysis, but the DAF banding patterns were very similar. Morphologically, these two cultivars were extremely difficult to identify. Screening 11 DAF octamer primers with the five Freedom series cultivars produced only monomorphic banding profiles. This was not surprising since each cultivar in the Freedom series is a sport that arose from another cultivar within that series and phenotypically they differ primarily only in bract color. The ASAP

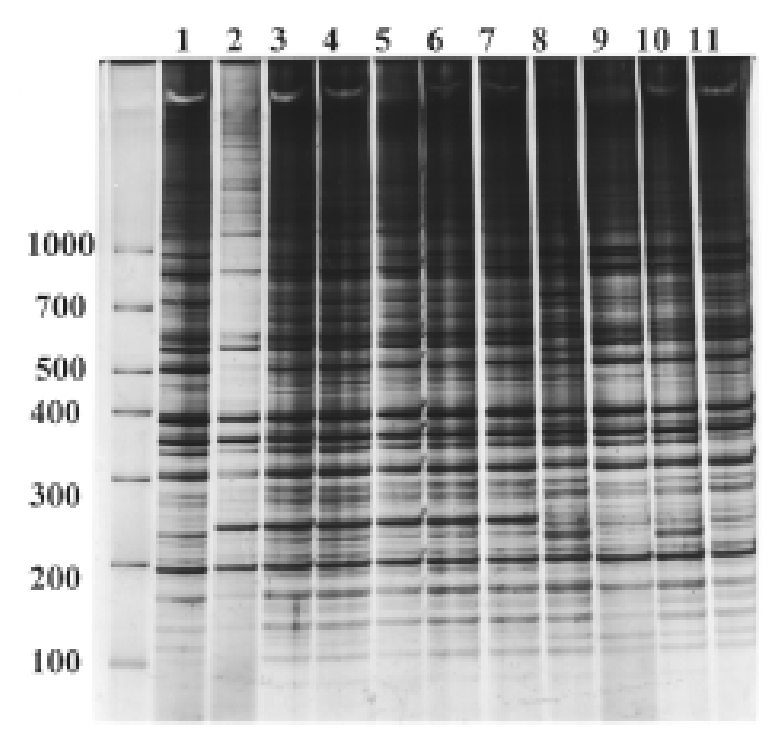

Fig. 1. DAF profiles of cultivars of poinsettia using the primer 8.7D (CCGAGCTG). Lane 1 = 'V-14 Glory', Lane $2=$ 'V-17 Angelika', Lane 3 = 'Peterstar Red', Lane 4 = 'Nutcracker Red', Lane $5=$ 'Supjibi', Lane $6=$ 'Petoy', Lane 7 = 'Darlyne', Lane 8 = 'Lilo Red', Lane 9 = 'Celebrate 2', Lane $10=$ 'Red Sails', Lane $11=$ 'Freedom Red'. Molecular weights are given in bp. 
method was therefore used to attempt to distinguish the closely related Freedom series cultivars and further separate 'Nutcracker Red' and 'Peterstar Red'.

To determine reproducibility of the ASAP amplification reaction for poinsettia, two DAF amplification reactions, one with primer $8.6 \mathrm{D}$ and the other with primer $8.7 \mathrm{D}$, were reamplified twice each in separate reactions with two mini-hairpin primers $\mathrm{HpB} 52$ and HpD4. The DNA templates used were 'Nutcracker Red' and 'Peterstar Red' from single extractions. The separate ASAP reactions were amplified in each of two thermocyclers, the twin-block and a model PTC 100 thermocycler (MJ Research, Watertown, Mass.). No differences were detected between ASAP patterns obtained in independent DNA amplifications using the same primer and template combination (Fig. 3). Patterns were consistent despite some variation in staining intensity of bands. Reproducibility has been verified repeatedly between extractions and amplifications of floriculture crops using the DAF (Cerny et al., 1996; Scott et al., 1996) and ASAP techniques (Caetano-Anollés and Gresshoff, 1996; Starman and Abbitt, 1997; Trigianoetal., 1998).

In contrast to DAF, the ASAP method generated complex polymorphic banding profiles that facilitated the separation of 'Nutcracker Red' from 'Peterstar Red' (Fig. 4). ASAP also distinguished the five cultivars of the Freedom series. Using eight ASAP primer combinations, 231 bands were generated and used for analysis (Table 2). The average number of bands $(\leq 1000 \mathrm{bp})$ per primer was 29 and ranged from 20 to 49 (Table 2). About $38 \%$ of the ASAP fragments scored were polymorphic. Of the five total profiles produced by each primer for the Freedom series, the greatest number of unique fingerprints per profile was two.

'Nutcracker Red' and 'Peterstar Red' were uniquely identified by amplification products generated with five of the eight primer combinations tested. Genetic relationships established by cluster analysis also were supported by numerical principal coordinate analysis (PCO) (Fig. 5). The Freedom series clustered together and 'Nutcracker Red' and 'Peterstar Red' were on a separate branch.

Similar results were obtained in a study of geranium cultivars. Using 10 octamer primers, DAF resulted in few polymorphisms between cultivars of seed and cutting geraniums, although ivy geraniums could be distinguished (Starman and Abbitt, 1997). However, the ASAP method generated complex polymorphic banding profiles separating all eight cultivars and cultivars within series.

The DAF and ASAP nucleic acid scanning techniques offer advantages in the identification of closely related taxa or cultivars within series when compared with other present DNA fingerprinting methods. Our results demonstrate the ease and the resolving power of the techniques in establishing cultivar identification and evaluating relationships among closely related cultivars of poinsettia. If primers are selected to yield highly polymorphic profiles, then the DAF technique can distinguish closely

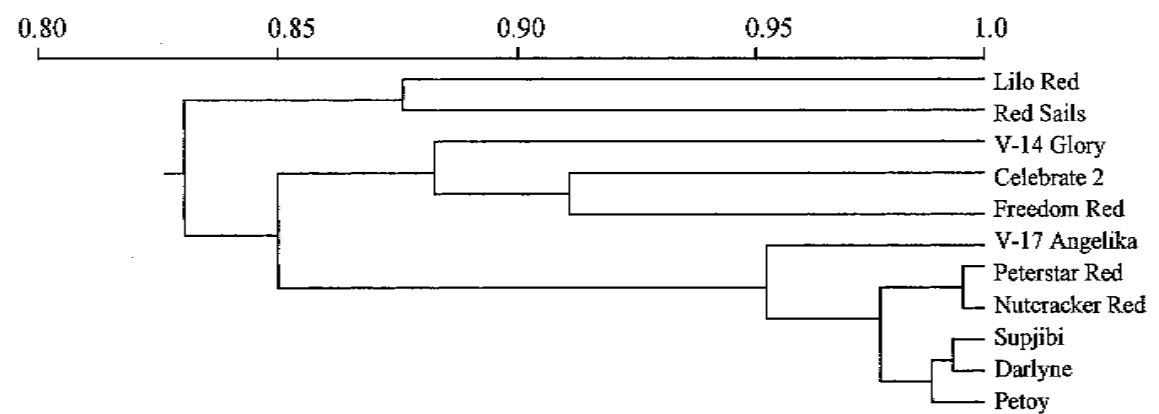

Fig. 2. Relationships among poinsettia cultivars using the UPGMA cluster analysis based on the Jaccard distance estimator.
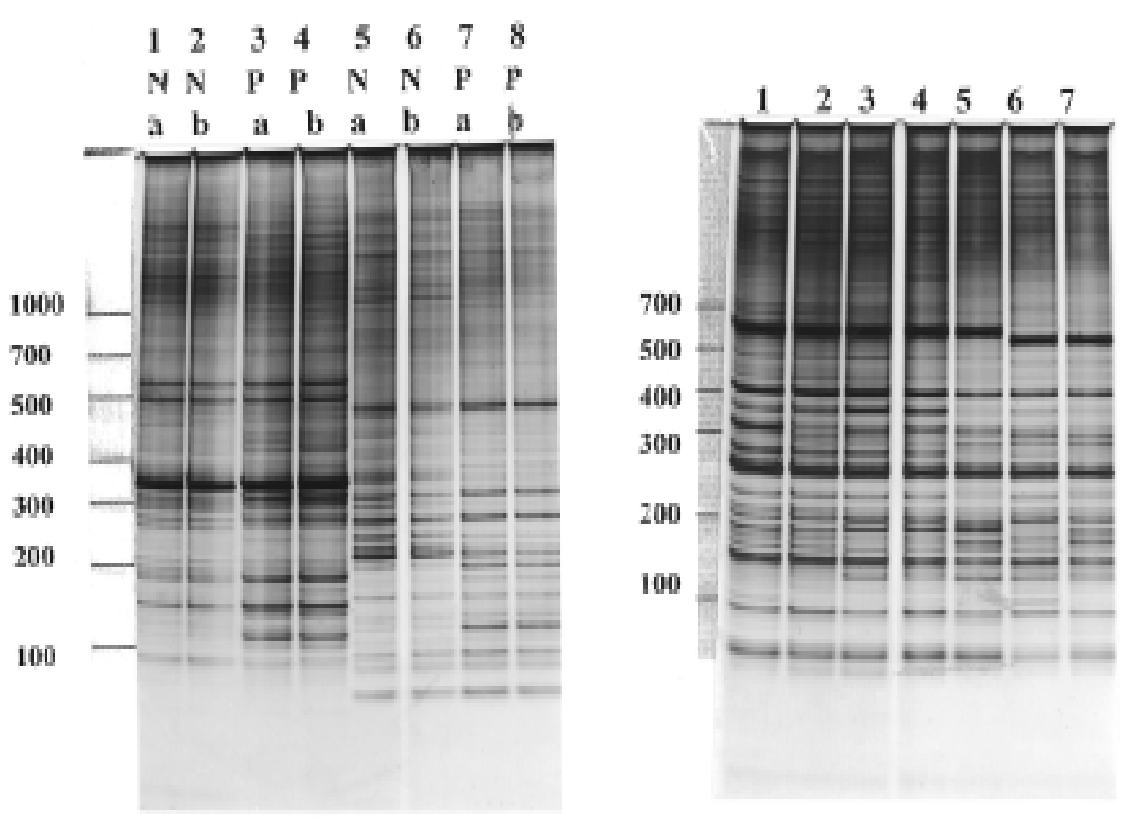

Fig. 3. Reproducibility of ASAP reactions in poinsettia. The DAF amplification reaction was the same using primer 8.6 D (GTAACGCC) with 'Nutcracker Red' (N) and 'Peterstar Red' (P) poinsettia. Lanes 1-4 were reamplified with HpB52 (GCGACAGC-ACA), and lanes 5-8 were reamplified with HpD4 (GCGATAGC$\mathrm{CCA}$ ). Lanes a and $\mathrm{b}$ were separate amplification reactions and amplified in two different thermocyclers. Lanes a were amplified in the Ericomp twin block thermocycler and lanes b were amplified in the PT 100 thermocycler.
Fig. 4. Polymorphic ASAP profiles of poinsettia cultivars using primer $8.7 \mathrm{D}$ (CCGAGCTG) followed by reamplification with primer $\mathrm{HpC} 19$ (GCGAGAGC-TCG). Lane 1 = 'Freedom Red', Lane 2 = 'Freedom Jingle Bells', Lane $3=$ 'Freedom Marble', Lane 4 = 'Freedom Pink', Lane $5=$ 'Freedom White', Lane $6=$ 'Nutcracker Red', Lane 7 = 'Peterstar Red'. Molecular weights are given in bp. 

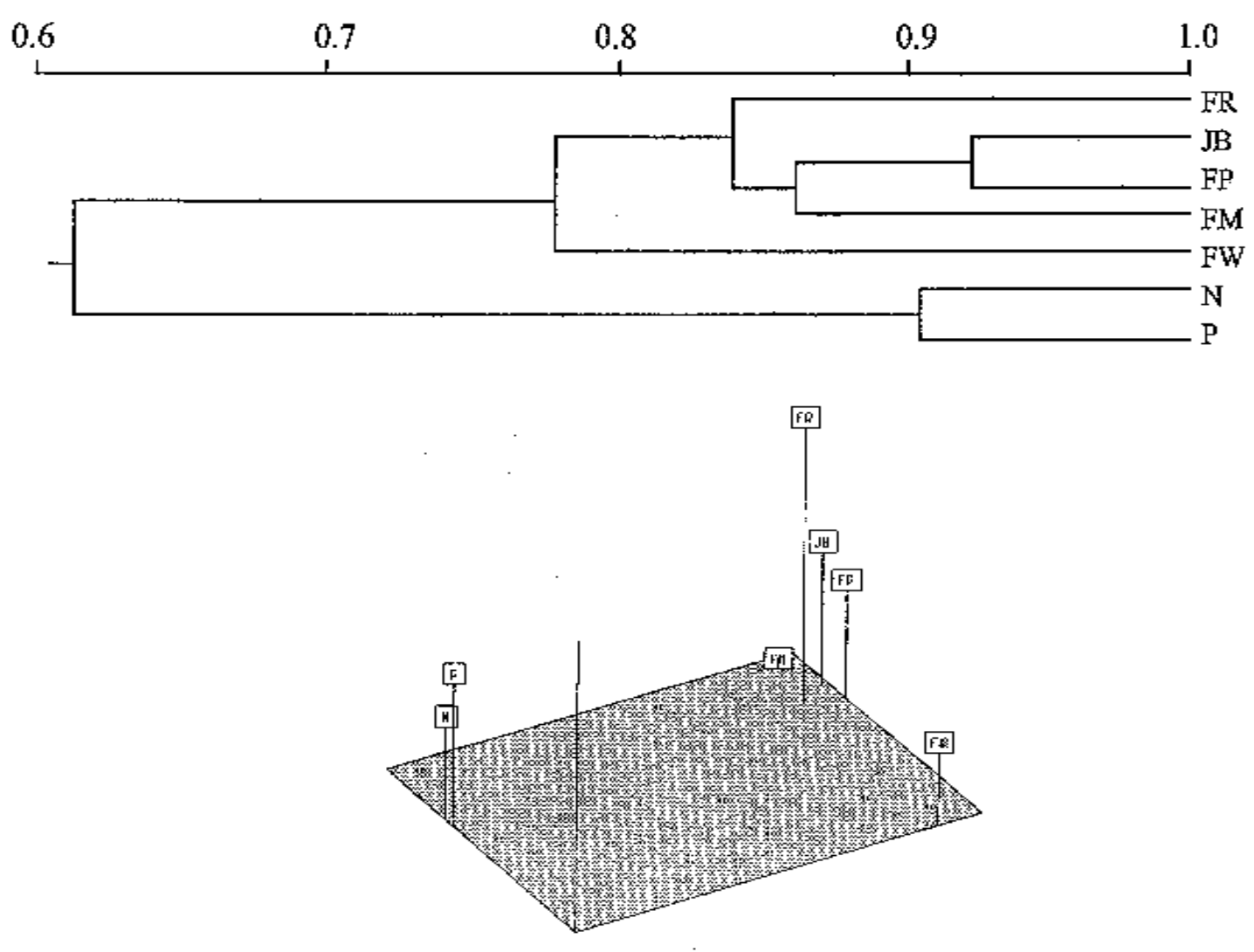

Fig. 5. Relationships among poinsettia cultivars using the UPGMA cluster analysis based on the Jaccard distance estimator, principal coordinate analysis dendrogram (top) and 3-dimensional graph (bottom). FR = 'Freedom Red', JB = 'Freedom Jingle Bells', FP = 'Freedom Pink', FM = 'Freedom Marble', FW $=$ 'Freedom White', $\mathrm{N}=$ 'Nutcracker Red', $\mathrm{P}=$ 'Peterstar Red'.

related cultivars within series. Alternatively, diagnostic amplification products for most cultivars within a series can be produced reliably and efficiently using relatively few primers and the ASAP technique.

\section{Literature Cited}

Bassam, B.J. and S. Bentley. 1995. Electrophoresis of polyester-backed polyacrylamide gels. BioTechniques 19(4):568-572.

Bassam, B.J., G. Caetano-Anollés, and P.M. Gresshoff. 1991. Fast and sensitive silver staining of DNA in polyacrylamide gels. Anal. Biochem. 196:80-83.

Caetano-Anollés, G., B.J. Bassam, and P.M. Gresshoff . 1991. DNA amplification fingerprinting using very short arbitrary oligonucleotide primers. Bio/Technology 9:553-557.

Caetano-Anollés, G. and P.M. Gresshoff . 1994. DNA amplification fingerprinting using arbitrary mini-hairpin oligonucleotide primers. Bio/ Technology 12:619-623.

Caetano-Anollés, G. and P.M. Gresshoff. 1996.
Generation of sequence signatures from DNA amplification fingerprints with mini-hairpin and microsatellite primers. BioTechniques 20:10441056.

Cerny, T.A., G. Caetano-Anollés, R.N. Trigiano, and T.W. Starman. 1996. Molecular phylogeny and DNA amplification fingerprinting of Petunia. Theor. Appl. Genet. 92:1009-1016.

Ecke, P. 1990. History of poinsettia varieties, p. 96100. In: H. Tayama and T.J. Roll (eds.). Tips on growing poinsettia. Coop. Ext. Serv., Ohio State Univ.

Jianhua, Z., M.B. McDonald, and P.M. Sweeney. 1997. Testing for genetic purity in petunia and cyclamen seed using random amplified polymorphic DNA markers. HortScience 32:246247.

Lee, I., M. Klopmeyer, I.M. Bartoszyk, D.E. Gundersen-Rindal, T. Chou, K.L. Thomson, and R. Eisenreich. 1997. Phytoplasma induced free-branching in commercial poinsettia cultivars. Nature Biotechnol. 15:178-182.

Ling, J.-T., R. Sauve, and N. Gawel. 1997. Identification of poinsettia cultivars using RAPD markers. HortScience 32:122-124.

Scott, M.C., G. Caetano-Anollés, and R.N. Trigiano. 1996. DNA amplification fingerprinting identifies closely related chrysanthemum cultivars. J. Amer. Soc. Hort. Sci. 121:1043-1048.

Starman, T.W. and S. Abbitt. 1997. Distinguishing geranium cultivars and evaluating their genetic relationships using Arbitrary Signatures from Amplification Profiles (ASAP). HortScience 32:1288-1291.

Trigiano, R.N., M.C. Scott, and G. Caetano-Anollés. 1998. Genetic signatures from amplification profiles characterize DNA mutation in somatic and radiation-induced sports of Chrysanthemum. J. Amer. Soc. Hort. Sci. 123:642-646.

Walker, C.A., Jr. and D.J. Werner. 1997. Isozyme and randomly amplified polymorphic DNA (RAPD) analyses of Cherokee rose and its putative hybrids 'Silver Moon' and 'Anemone'. J. Amer. Soc. Hort. Sci. 122:659-664.

Wolff, K. and J. Peters-Van Rijn. 1993. Rapid detection of genetic variability in chrysanthemum (Dendranthema grandiflora Tzvelev) using random primers. Heredity 71:335-341. 